\title{
Study on the Characteristics of Electromagnetic Noise of Axial Flux Permanent Magnet Synchronous Motor
}

\author{
Wei Wang, ${ }^{1}$ Hang Wang, ${ }^{1}$ and Hamid Reza Karimi ${ }^{2}$ \\ ${ }^{1}$ College of Engineering, Bohai University, Jinzhou 121013, China \\ ${ }^{2}$ Department of Engineering, Faculty of Engineering and Science, The University of Agder, 4898 Grimstad, Norway \\ Correspondence should be addressed to Wei Wang; wangwei_yang@126.com
}

Received 19 December 2013; Accepted 18 January 2014; Published 27 February 2014

Academic Editor: Ming Liu

Copyright (c) 2014 Wei Wang et al. This is an open access article distributed under the Creative Commons Attribution License, which permits unrestricted use, distribution, and reproduction in any medium, provided the original work is properly cited.

\begin{abstract}
The normal electromagnetic force distribution in stator system of axial flux permanent magnet synchronous motor (PMSM) has been thoroughly analyzed in this paper. The main composition of force wave causing vibration and noise has been proposed, and at the same time a calculation method of stator natural frequency of axial flux PMSM has been raised. Through this method electromagnetic force wave, natural frequency, vibration response, and electromagnetic noise of a $15 \mathrm{~kW}$ axial flux PMSM with 22 poles and 24 slots have been calculated; calculations and measured values are consistent by comparison. The noise sources of axial flux PMSM have been found in this paper, which provides the theoretical support for the suppression of electromagnetic noise of axial flux PMSM.
\end{abstract}

\section{Introduction}

Currently, noise, water pollution, and exhaust gas have been the three public hazards of environmental pollution. With the implementation of ISO14001 standard, the motor noise level has been listed as an important indicator of measuring its quality. Therefore, low noise motor will surely become one of the key products to in the 21st century. Internationally, for the motor, the merits and defects of noise control have become a domain factor of market competition for electronic motor, which has been widely recognized by this industry. The level of controlling motor noise has attracted more and more attention of manufacturers and users. And the laws and regulations connected with the working environment noise are becoming more rigid.

Various reasons cause the motor vibration, which are mainly divided into electromagnetic noise, mechanical noise, and aerodynamic noise. A research on how to apply effective fault diagnosis method to make noise fault diagnosis is very significant [1-8]. And the first problem to be solved is how to effectively calculate the vibration and noise of the motor. Compared with the electrical excitation motors, permanent magnet motors, especially rare earth permanent magnet motors, have simple structure, reliable operation, small volume, light weight, low loss, high efficiency, and diverse shapes and sizes as well as other remarkable advantages [5]. PMSM with multiphase, multipole, and few slots (especially the ratio of poles to slots was 1 to 1 ) has been applied more and more widely at present. However, compared with the traditional motor, the number and amplitude of air gap harmonics magnetic field, the intensity and frequency of electromagnetic noise, and the adapted suppression methods of this kind of PMSM have distinctive difference.

Although the research about the electromagnetic vibration and noise of motors has made great achievements [6-25], there are still no mature methods to analyze and calculate the modal and natural frequency of axial flux PMSM. Thus this paper will explore the electromagnetic noise of PMSM with multipole and few slots.

\section{The Generation Mechanism of Electromagnetic Noise}

The normal electromagnetic force, which consists of different frequencies and different distribution rotation force waves 
caused by the mutual action of stator and rotor and acting on the inner surface of stator core, is the main source of motors vibration and electromagnetic noise.

According to Maxwell law, the instantaneous value of normal electromagnetic force per unit area can be expressed as

$$
p_{r}(\theta, t)=\frac{b^{2}(\theta, t)}{2 \mu_{0}}
$$

where $\mu_{0}$ is the permeability of vacuum and $b(\theta, t)$ is the air gap flux density, which was superposed by stator flux and rotor flux, and can be expressed as

$$
\begin{aligned}
b(\theta, t)= & b_{\nu}(\theta, t)+b_{\mu}(\theta, t) \\
= & \sum_{\nu} B_{\nu} \cos \left(\nu \theta-\omega_{1} t-\phi_{\nu r}\right) \\
& +\sum_{\mu} B_{\mu} \cos \left(\mu \theta-\omega_{\mu} t-\phi_{\mu r}\right),
\end{aligned}
$$

where $b_{\nu}(\theta, t), b_{\mu}(\theta, t)$, respectively, represent the instantaneous value of flux density produced at stator side and rotor side which changed with position angle and time. Then substitute (2) into (1), the following equation can be obtained:

$$
\begin{gathered}
p_{r}(\theta, t) \frac{1}{2 \mu_{0}}\left\{\sum_{\nu} B_{\nu}^{2} \cos ^{2}\left(\nu \theta-\omega_{1} t-\phi_{\nu r}\right)\right. \\
+\sum_{\mu} B_{\mu}^{2} \cos ^{2}\left(\mu \theta-\omega_{\mu} t-\phi_{\mu r}\right) \\
+2 \sum_{\nu_{1}, \nu_{2}} B_{\nu_{1}} B_{\nu_{2}} \cos \left(\nu_{1} \theta-\omega_{1} t-\phi_{\nu_{1} r}\right) \\
\times \cos \left(\nu_{2} \theta-\omega_{1} t-\phi_{\nu_{2} r}\right) \\
+2 \sum_{\nu, \mu} B_{\nu} B_{\mu} \cos \left(\nu \theta-\omega_{1} t-\phi_{\nu r}\right) \\
\times \cos \left(\mu \theta-\omega_{\mu} t-\phi_{\mu r}\right) \\
+2 \sum_{\mu_{1}, \mu_{2}} B_{\mu_{1}} B_{\mu_{2}} \cos \left(\mu_{1} \theta-\omega_{\mu_{1}} t-\phi_{\mu_{1} r}\right) \\
\left.\times \cos \left(\mu_{2} \theta-\omega_{\mu_{2}} t-\phi_{\mu_{2} r}\right)\right\} .
\end{gathered}
$$

According to (3), the normal electromagnetic force acting on the stator tooth consists of five parts. And the force waves with large amplitude and low order are the primary sources. To PMSM, the electromagnetic force waves, caused by the interaction between rotor and stator harmonic magnetic flux density (the fourth item) and the interaction of various harmonic magnetic flux density produced by permanent magnet (the fifth item), are the major sources of electromagnetic noise.
Under plane radiation, the power of electromagnetic noise caused by electromagnetism acting on stator teeth can be expressed as

$$
W=2 \rho c \pi^{2} f_{r}^{2} Y^{2} S_{0}
$$

where $\rho$ is the medium density of sound, $c$ is the velocity of sound in medium density, $f_{r}$ is the frequency of electromagnetic force wave, and $S_{0}$ is the vibrating area in vertical direction of the sound wave propagation. $Y$ is the displacement of vibration under stator electromagnetic force and $Y=P^{\prime} / K-\omega_{r}^{2} M$ when damping neglected. $P^{\prime}$ is the amplitude of electromagnetic force wave acting on stator teeth. $K$ is the stiffness of stator system. $M$ is the mass of fixed system. $\omega_{r}$ is the angular frequency of electromagnetic force wave

\section{The Analysis of Electromagnetic Force Wave of Axial Flux PMSM}

The rotating force wave per unit area, causing the electromagnetic noise, can be expressed as

$$
p_{r}(\theta, t)=\sum_{r} P_{r} \cos \left(\omega_{r} t-r \theta+\varphi_{n}\right)
$$

where $P_{r}, r(r=1,2,3, \ldots)$ represent the amplitude and the order of electromagnetic force wave.

In a moment of time, the distribution of normal electromagnetic force from zero to third harmonic of axial flux PMSM is shown in Figure 1, where solid dots stand for outward and crossing lines stand for inward. Different sizes of solid dots and crossing lines signify the size and direction of electromagnetic force.

After further clarification of fourth and fifth formulas in formula (3), the main values of electromagnetic force in the realm of amplitude, order, and frequency can be obtained.

$$
\begin{aligned}
& p_{r}(\theta, t) \\
& \begin{array}{c}
\approx \frac{1}{2 \mu_{0}}\left\{2 \sum_{\nu, \mu} B_{\nu} B_{\mu} \cos \left(\nu \theta-\omega_{1} t-\phi_{\nu r}\right)\right. \\
\times \cos \left(\mu \theta-\omega_{\mu} t-\phi_{\mu r}\right) \\
+2 \sum_{\mu_{1}, \mu_{2}} B_{\mu_{1}} B_{\mu_{2}} \cos \left(\mu_{1} \theta-\omega_{\mu_{1}} t-\phi_{\mu_{1} r}\right) \\
\left.\times \cos \left(\mu_{2} \theta-\omega_{\mu_{2}} t-\phi_{\mu_{2} r}\right)\right\} \\
=\frac{1}{2 \mu_{0}} \sum_{\nu, \mu} B_{\nu} B_{\mu} \\
\times \cos \left[(\nu+\mu) \theta-\left(\omega_{1}+\omega_{\mu}\right) t-\left(\phi_{\nu r}+\phi_{\mu r}\right)\right]
\end{array}
\end{aligned}
$$


TABLE 1: Main normal electromagnetic force.

\begin{tabular}{|c|c|c|c|}
\hline \multirow{2}{*}{ Harmonic source } & \multicolumn{3}{|c|}{ Item } \\
\hline & Amplitude & Frequency & Order \\
\hline The interaction between rotor and stator harmonic & $\left(1 / 2 \mu_{0}\right) B_{\nu} B_{\mu}$ & $\begin{array}{c}2 k_{1} f_{1} \\
2\left(k_{1}+1\right) f_{1}\end{array}$ & $\begin{array}{l}{\left[\left(2 k_{1}+1\right) p_{1} \pm k_{2} Z_{1}\right] t-v_{p}} \\
{\left[\left(2 k_{1}+1\right) p_{1} \pm k_{2} Z_{1}\right] t+v_{p}}\end{array}$ \\
\hline The interaction of different rotor harmonic & $\left(1 / 2 \mu_{0}\right) B_{\mu 1} B_{\mu 2}$ & $\begin{array}{c}2\left(k_{1}-k_{3}\right) f_{1} \\
2\left(k_{1}+k_{3}+1\right) f_{1}\end{array}$ & $\begin{array}{c}{\left[2\left(k_{1}-k_{3}\right) p_{1} \pm\left(k_{2} \pm k_{4}\right) Z_{1}\right] t} \\
{\left[2\left(k_{1}+k_{3}+1\right) p_{1} \pm\left(k_{2} \pm k_{4}\right) Z_{1}\right] t}\end{array}$ \\
\hline
\end{tabular}

Remark: $k_{1}, k_{2}, k_{3}, k_{4}$ are defined as $0,1,2,3, \ldots$, respectively $f_{1}$ is fundamental frequency; $v_{p}$ is harmonic order produced by stator winding.

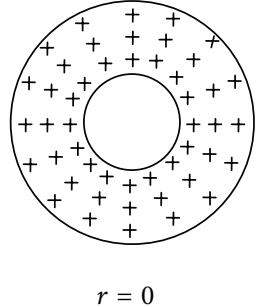

(a)

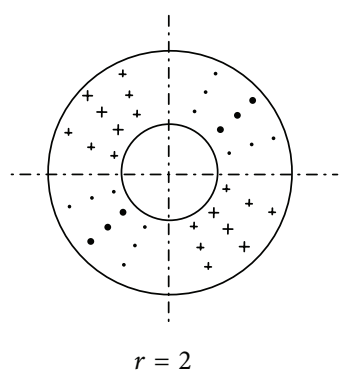

(c)

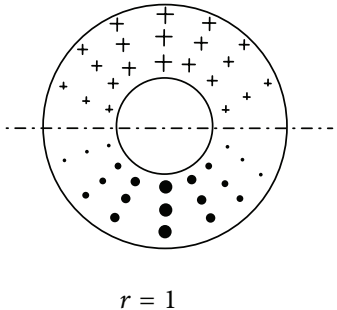

(b)

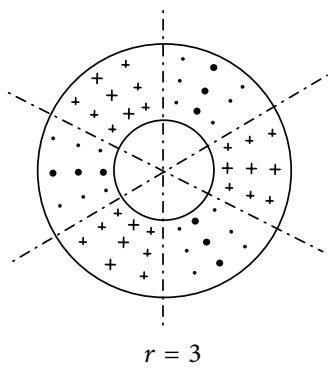

(d)
Figure 1: Normal electromagnetic forces distribution of axial flux permanent magnet synchronous motor.

$$
\begin{aligned}
& +\frac{1}{2 \mu_{0}} \sum_{\mu_{1}, \mu_{2}} B_{\mu_{1}} B_{\mu_{2}} \\
& \quad \times \cos \left[\left(\mu_{1}+\mu_{2}\right) \theta-\left(\omega_{\mu_{1}}+\omega_{\mu_{2}}\right) t-\left(\phi_{\mu_{1} r}+\phi_{\mu_{2} r}\right)\right] .
\end{aligned}
$$

The electromagnetic noise of axial flux PMSM with the characteristics of 22 poles and 24 slots, six phases, dual-Y, and $30^{\circ}$ shifts was studied in this paper. The main normal electromagnetic force was illustrated in formula (6) and its amplitude, order, and frequency were shown in Table 1.

As for PMSM, the main electromagnetic force was from the interactions of different harmonic waves of rotor in which the electromagnetic force generated from the interactions between fundamental harmonic magnetic flux density and first-order tooth harmonic magnetic density of permanent magnet was the most important. The frequency of the electromagnetic force was 2 multiple of fundamental frequency. The order of the electromagnetic force $r$ is

$$
r=\left(p_{1}+\left(p_{1}-Z_{1}\right)\right) t=\left(2 p_{1}-Z_{1}\right) t .
$$

A $15 \mathrm{~kW}$ axial flux PMSM with 22 poles and 24 slots

\begin{tabular}{|c|c|c|c|c|c|c|c|}
\hline \multirow{2}{*}{$v_{1}$} & \multicolumn{7}{|c|}{$\mu_{1}$} \\
\hline & $(9)_{3}$ & 11 & $(-13)_{1}$ & 33 & $(35)_{1}$ & {$[-37]_{1}$} & 55 \\
\hline 5 & $4 / 2 f_{1}$ & & & & & & \\
\hline-7 & & $4 / 2 f_{1}$ & & & & & \\
\hline 11 & $2 / 2 f_{1}$ & & $2 / 2 f_{1}$ & & & & \\
\hline$(-13)_{1}$ & $4 / 4 f_{1}$ & $2 / 2 f_{1}$ & & & & & \\
\hline 17 & & & $4 / 2 f_{1}$ & & & & \\
\hline 29 & & & & $4 / 2 f_{1}$ & & & \\
\hline-31 & & & & $2 / 4 f_{1}$ & $4 / 2 f_{1}$ & & \\
\hline$(35)_{1}$ & & & & $2 / 2 f_{1}$ & & & \\
\hline$[-37]_{1}$ & & & & $4 / 4 f_{1}$ & $2 / 2 f_{1}$ & & \\
\hline 41 & & & & & & $4 / 2 f_{1}$ & \\
\hline
\end{tabular}
was taken as an example in this paper. The frequency and
TAble 2: Main electromagnetic force with 22 Poles and 24 Slots.

order of the electromagnetic force were shown in Table 2, where ( ) stands for first slot harmonic, [ ] stands for second slot harmonic, the subscripts out of parentheses represent that the slot harmonic in parentheses was generated by its interactions, and $\nu_{1}, \mu_{1}$ were the harmonic order of stator side and rotor. Also, low-order harmonic force wave would be generated from the interactions between $\mu_{1}$ and $\mu_{2}$. The harmonic order with bold font also represented $\nu_{1}$ and $\mu_{2}$.

As seen from Table 2, firstly, the electromagnetic force wave, which order is 2 and frequency is $2 f_{1}$, has been generated from the interactions between 11th fundamental harmonic of permanent magnet and first slot harmonic magnetic flux density $(-13)$ of stator and rotor. Secondly, loworder force wave generated from the interactions between 11th fundamental harmonic of stator and first slot harmonic magnetic flux density $(-13)$ of rotor was equally important. Thirdly, another electromagnetic force wave was the second gear force wave (the frequency was $2 f_{1}$ ) which was generated from the interactions between 33th harmonic (the flux density was 3 times of fundamental wave) and 35th step first slot harmonic wave of rotor. The above will be the largest sources of force wave.

The power spectral density of electromagnetic force wave (the step was less than 4) could be derived by using analytic method. The fundamental frequency $\left(f_{1}\right)$ of motor was $82.5 \mathrm{~Hz}$. As seen in Figure 2, each frequency of electromagnetic force was an even multiple of fundamental frequency, where the energy of electromagnetic force whose frequency was 2 multiple of fundamental frequency was the biggest, which was consistent with analysis of Table 2. 


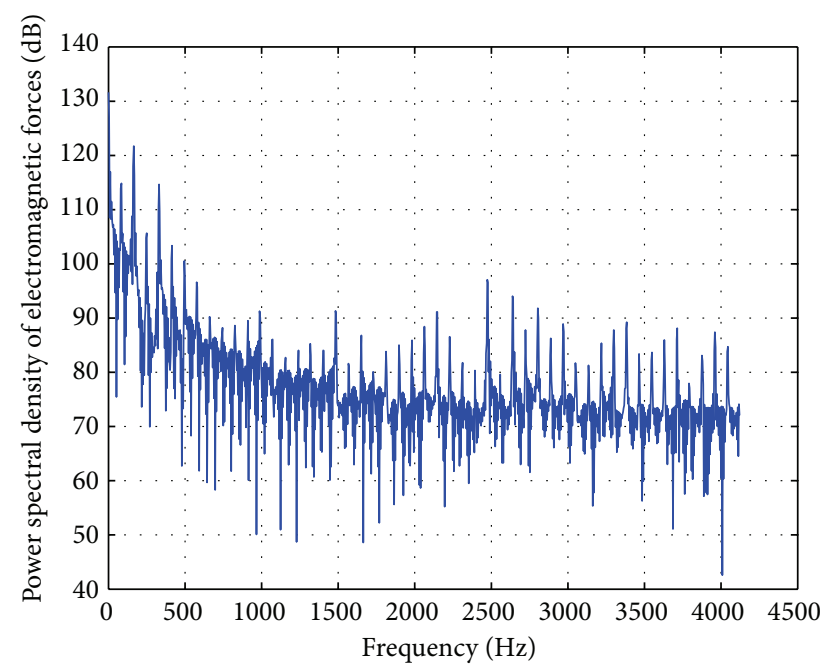

Figure 2: Power spectral density of electromagnetic forces used analytical methods.

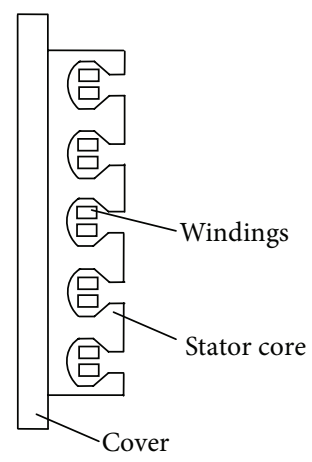

Figure 3: Stator system of axial flux PMSM.

\section{The Analysis of Natural Frequency of Stator System of Axial Flux PMSM}

4.1. The Analysis of Natural Frequency. The vibrating direction of axial flux PMSM stator system was axial. Based on the analysis, the vibration characteristics of stator yoke were similar to doughnut-shaped steel plate, so choosing the circular plate as a replacement. The stator structure and the stress direction of stator tooth were shown in Figures 3 and 4.

With reference to calculative method of stator natural frequency for radial flux PMSM, the calculation formula of stator natural frequency of axial flux PMSM was presented as follows:

$$
f_{m}=\frac{1}{2 \pi} \sqrt{\frac{K_{m}^{(c)}+K_{m}^{(f)}}{\Delta_{w} M_{m}^{(c)}+\Delta_{f} M_{m}^{(f)}}},
$$

where $K_{m}^{(c)}$ is the equivalent stiffness of stator core, $K_{m}^{(f)}$ is the equivalent stiffness of the cover, $M_{m}^{(c)}$ is the equivalent mass of stator core, $M_{m}^{(f)}$ is the equivalent mass of the cover, $\Delta_{\omega}=1+\left(M_{t}+M_{w}\right) / M_{m}^{(c)}$ is the additional coefficient of core mass, $M_{t}, M_{w}$ is the mass of stator tooth and stator winding,

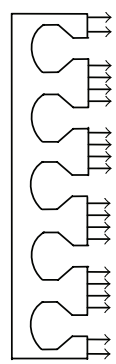

FIGURE 4: Stress direction of stator tooth of axial flux PMSM stator system of axial flux PMSM.

$\Delta_{f}=1+M_{f} / K_{m}^{(f)}$ is the additional coefficient of the cover, and $M_{f}$ is the mass of shell.

From (8), we can see that the key to getting stator natural frequency was how to determine the equivalent stiffness of iron core and cover in different vibrational modes.

When computed through the distribution of the quality system and the centralized quality system, the calculation formula of natural frequency of annular plate was presented as follows:

$$
\begin{aligned}
& f_{m}=\frac{a_{n s}}{2 \pi a^{2}} \sqrt{\frac{D}{\rho_{A}}} \\
& f_{m}=\frac{1}{2 \pi} \sqrt{\frac{K_{m}}{M_{m}}},
\end{aligned}
$$

where $D$ is the bending rigidity of plate and $E$ is the modulus of elasticity of plate. $h$ is the thickness of laminated plate and $\mu$ is Poisson's ratio. $a$ is the outer radius of annular plates, $\rho_{A}$ is the surface density of circular plate with a radius of $a$, and $a_{n s}$ is the frequency constants, determined by boundary conditions, vibrational mode, and the ratio of inside to outside diameter.

According to (9),

$$
f_{m}=\frac{a_{n s}}{2 \pi a^{2}} \sqrt{\frac{D}{\rho_{A}}}=\frac{1}{2 \pi} \sqrt{\frac{a_{n s}^{2} D \pi\left(a^{2}-b^{2}\right)}{a^{4} \rho_{A} \pi\left(a^{2}-b^{2}\right)}}=\frac{1}{2 \pi} \sqrt{\frac{K_{m}}{M_{m}}},
$$

where

$$
\begin{aligned}
& K_{m}=\frac{a_{n s}^{2} D \pi\left(a^{2}-b^{2}\right)}{a^{4}} \\
& M_{m}=\rho_{A} \pi\left(a^{2}-b^{2}\right),
\end{aligned}
$$

where $b$ the inside radius of the annular plate.

4.2. The Calculations of Stator System Natural Frequency of a $15 \mathrm{~kW}$ Axial Flux PMSM. The natural frequency of a $15 \mathrm{~kW}$ axial flux PMSM was calculated in this paper. The structure parameters of stator system were listed in Table 3 and the computational results of equivalent stiffness and natural frequency were listed in Table 4 . To verify the effectiveness 


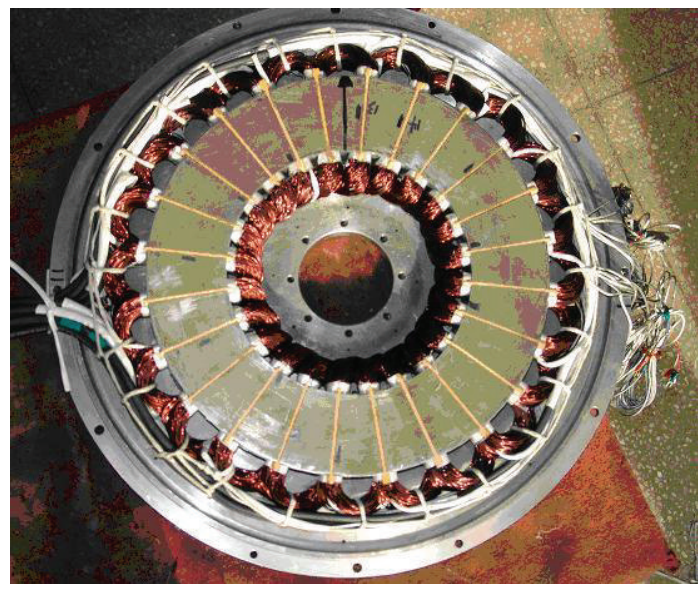

FIGURE 5: Stator system for $15 \mathrm{~kW}$ motor example of a figure caption.

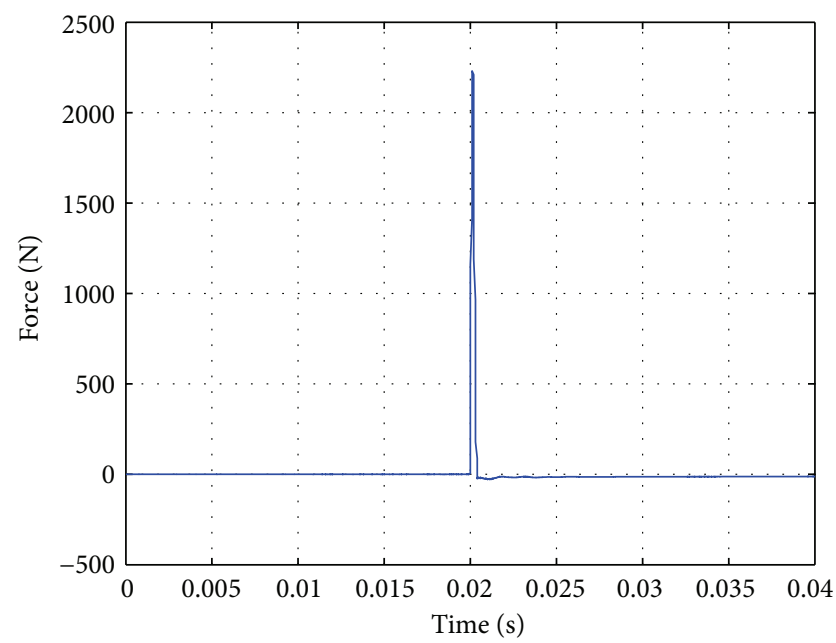

FIgURE 6: Excitation signal imposed on stator system.

TABLe 3: Parameters of stator system of $15 \mathrm{~kW}$ motor.

\begin{tabular}{lc}
\hline Parameters & Value \\
\hline Outerdiameter of stator & $250 \mathrm{~mm}$ \\
Innerdiameter of stator & $144 \mathrm{~mm}$ \\
Height of iron core yoke & $12.7 \mathrm{~mm}$ \\
Weight of statorteeth & $2.4 \mathrm{~kg}$ \\
Weight of iron core yoke & $2.9 \mathrm{~kg}$ \\
Weight of stator winding & $3.4 \mathrm{~kg}$ \\
\hline
\end{tabular}

of the calculation method presented in this paper, the $15 \mathrm{~kW}$ axial flux PMSM was tested by using PULSE system produced by Denmark B\&K company. Figure 5 was stator system for $15 \mathrm{~kW}$ motor. Figures 6, 7, and 8 were, respectively, curves of excitation, response, and transfer functions. According to Figure 8 , the natural frequency of stator system can be obtained, and test results were listed in Table 4.

The natural frequency of stator system must be away from the electromagnetic force wave; otherwise the motor will cause resonance, resulting in serious consequences.

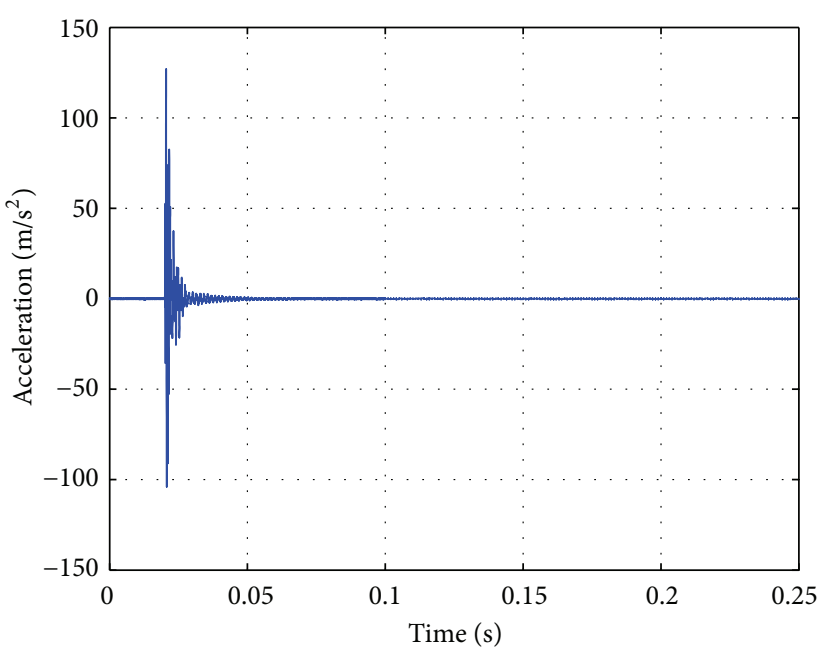

FIGURE 7: Response by stator system natural frequency experiment.

TABLE 4: Calculation and test results for natural frequencies of stator core of $15 \mathrm{~kW}$ motor.

\begin{tabular}{lcccc}
\hline$(n, s)$ & $K_{m}^{(c)} / \mathrm{M} \mathrm{N} \cdot \mathrm{m}^{-1}$ & $f_{\mathrm{ma}} / \mathrm{Hz}$ & $f_{\mathrm{me}} / \mathrm{Hz}$ & $\mathrm{err} / \%$ \\
\hline$(2,0)$ & 91.75 & 258.3 & 280 & -7.75 \\
$(3,0)$ & 777.42 & 691.2 & 675 & 2.40 \\
$(1,1)$ & 238.67 & 1174.5 & 1135 & 3.48 \\
$(4,0)$ & 2746.05 & 1265.0 & 1313 & -3.65 \\
$(5,0)$ & 6943.36 & 1985.2 & 2040 & -2.68 \\
\hline
\end{tabular}

Remark: $n$ is pitch diameter number; $s$ is pitch circle number; $f_{\text {ma }}$ is calculation natural frequency; $f_{\mathrm{me}}$ is measured value of natural frequency; err is relative error.

\section{The Analysis of Electromagnetic Noise of Axial Flux PMSM}

5.1. The Dynamic Response of Motor. The vibration of motor caused by normal electromagnetic force acting on stator system is the main source of electromagnetic noise and an analytic relationship exists between the vibration and noise. Therefore it is very important to calculate the vibration of motor. When the motor was at work, vibration at every point was caused all by different electromagnetic forces, which synthesized by vibration waveform of different amplitudes and different frequencies. When a lumped parameter mechanical system suffered a harmonic force with $\omega_{r}$ frequency and $P_{r s}$ amplitude, the vibration velocity of the system can be expressed as follows:

$$
\dot{Y}=\frac{\omega_{r} P_{r s}}{\left(K_{r}^{(c)}+K_{r}^{(f)}\right)-\omega_{r}^{2}\left(\Delta_{w} M_{m}^{(c)}+\Delta_{f} M_{m}^{(f)}\right)},
$$

where $K_{r}^{(c)}, K_{r}^{(f)}$ is equivalent stiffness of stator core and shields with the same number between number of pitch diameter and force wave.

The spectrum curve of vibrator acceleration of motor cover was obtained through experiment, which is shown in Figure 9. We can obtain the amplitude of vibration acceleration in maximal frequency from curve. Calculation and 


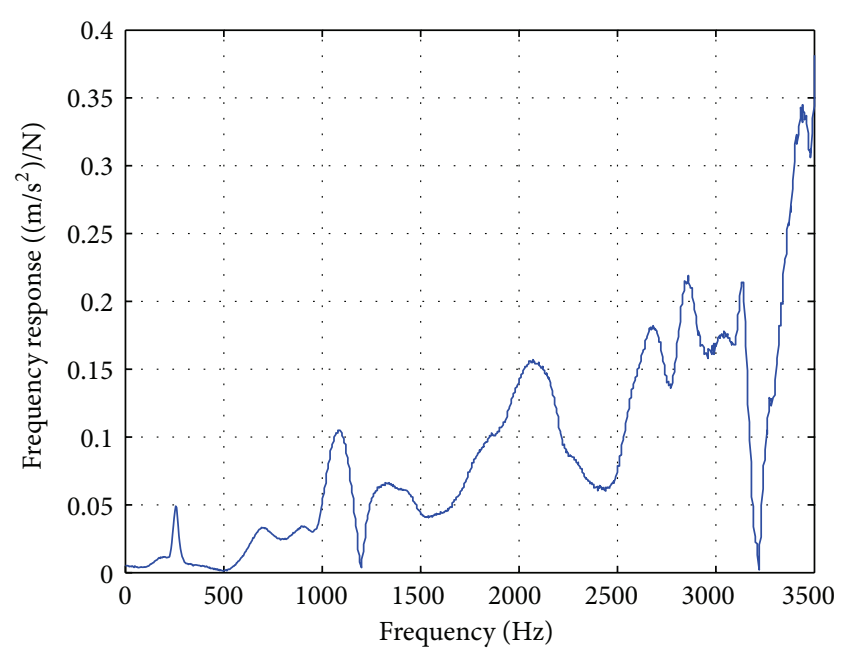

FIGURE 8: Transfer function by stator system natural frequency experiment.

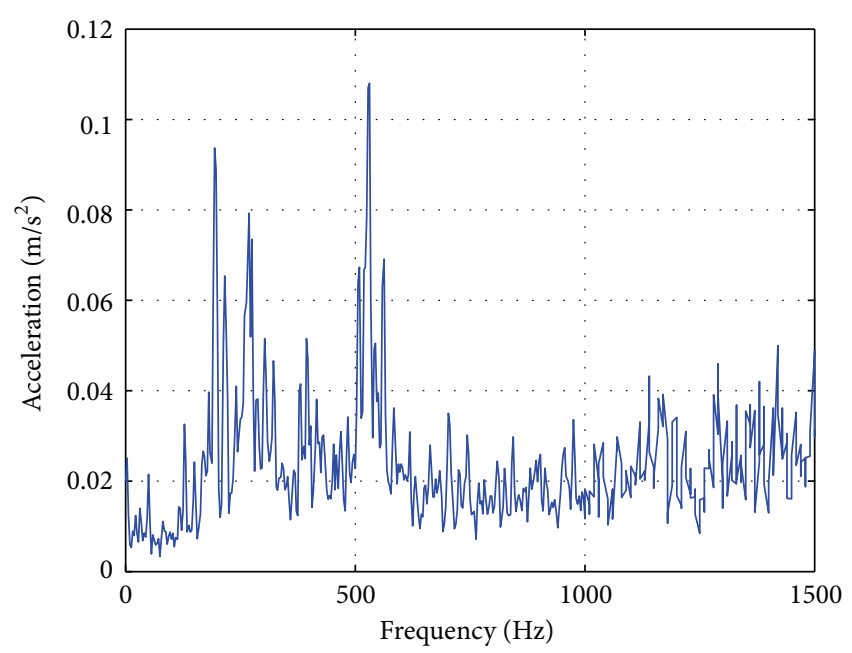

FIGURE 9: Spectrogram of vibration accelerations of motor cover.

measured value of vibration acceleration of motor shield were listed in Table 5.

The most important frequency component of the vibration acceleration level is $165 \mathrm{~Hz}$ and $330 \mathrm{~Hz}$. From Table 5, the calculate errors $-5.2 \%$ and $-0.47 \%$ indicate that the calculation results are consistent with the actual value.

5.2. The Electromagnetic Noise. Four steps must be completed before obtaining electromagnetic noise: calculating magnetic field and its harmonic, calculating normal electromagnetic force, calculating natural frequency and vibratory response of stator system, and calculating noise power level. On the basis of the previous three steps, you can successfully get the electromagnetic noise of the motor. Under nonloaded operation, the electromagnetic noise of axial flux PMSM was calculated by author edited programming, and at the same time the electromagnetic noise of the motor was measured

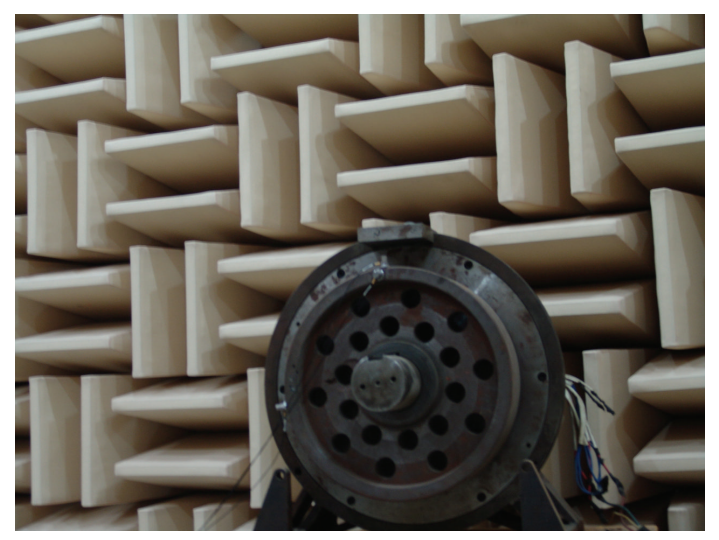

Figure 10: Experiment of $15 \mathrm{~kW}$ motor.

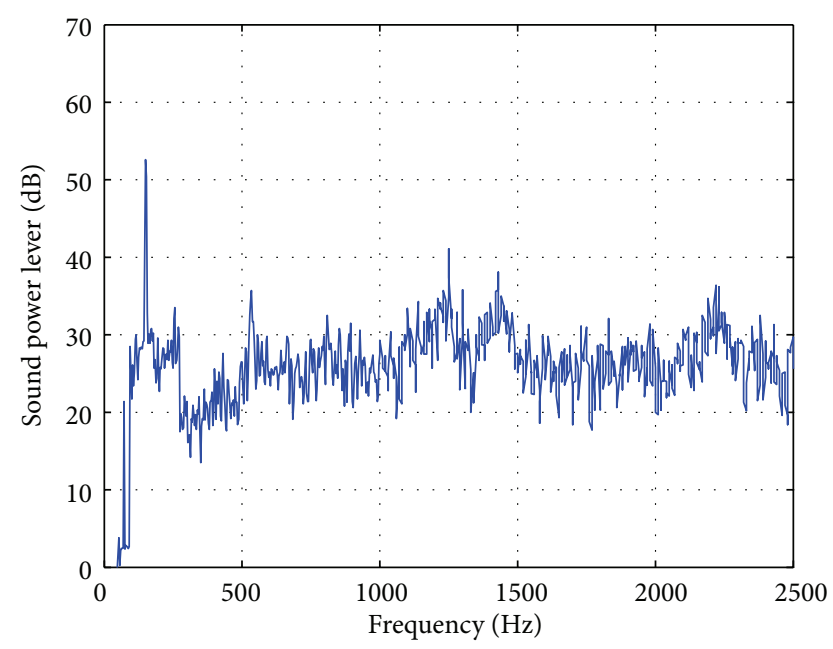

FIGURE 11: Spectrum of electromagnetic noise sound power lever $L_{I}$ of $15 \mathrm{~kW}$ motor.

in an anechoic chamber which is shown in Figures 10 and 11. And the test value and calculated value were listed in Table 6 .

The calculation results of acoustic noise in Table 6 have been modified, and the correction factor is 1.082 . The noise of $165 \mathrm{~Hz}$ is the most significant from the measured spectrum of acoustic noise, and theoretical calculations have the same conclusion. So rationality about analysis and calculation methods of axial flux PMSM electromagnetic noise mentioned by this paper has been proved.

\section{Conclusion}

The methods of analyses and calculation for electromagnetic vibration and noise have been researched in this paper. Using a $15 \mathrm{~kW}$ axial flux PMSM with 22 poles and 24 slots as an example, a verification calculation has been completed. The conclusions are illustrated.

(1) The direction of electromagnetic vibration: the direction of electromagnetic vibration was axial; thus typical estimation method for calculating electromagnetic vibration is not suitable. 
TABLE 5: Calculated and experimental values of accelerations level of $15 \mathrm{~kW}$ motor.

\begin{tabular}{lcccc}
\hline Item & \multicolumn{5}{c}{ Value } \\
\hline Frequency/Hz & 165 & 330 & 495 & 825 \\
Calculation/dB & 94.5 & 84.1 & 82.3 & 62.36 \\
Measured value/dB & 99.7 & 84.5 & 78.1 & 74.66 \\
Error/\% & -5.2 & -0.47 & 5.3 & 16.4 \\
\hline
\end{tabular}

TABLE 6: Comparation between calculated and measured values of Sound power lever.

\begin{tabular}{lccc}
\hline Frequency/Hz & $\begin{array}{c}\text { Calculation after } \\
\text { correction/dB (A) }\end{array}$ & $\begin{array}{c}\text { Measured } \\
\text { value/dB (A) }\end{array}$ & Error/\% \\
\hline 165 & 72.60 & 72.6 & 0 \\
330 & 59.73 & 59.1 & 1.06 \\
660 & 48.15 & 48.5 & -0.7 \\
\hline Combining & 72.6 & 72.6 & 0 \\
\hline
\end{tabular}

(2) The stator system structure of axial flux PMSM: the stator system of axial flux PMSM can be equivalent to annular steel plate and vibration mode was indicated by the number of pitch diameter and pitch, where the stator core thickness replaced with annular plate of stator yoke to calculate the height, teeth of the stator, and winding as additional quality were included in the stator core; shell as additional quality was included in the shield.

(3) The frequency of electromagnetic noise and vibration: the frequencies of electromagnetic noise and vibration were even multiple of fundamental wave. The frequency of vibration with highest energy was 2 times of fundamental frequency, which was caused by the normal electromagnetic force with frequency of double fundamental frequency. The main components of the electromagnetic force are listed below.

(a) One of the main components of the electromagnetic force: the low order force was caused by the interaction between fundamental flux density of permanent magnet and first-order slot harmonic magnetic density of rotor and stator.

(b) Another one of the main components of the electromagnetic force: the low order force was caused by the interaction between fundamental flux density of stator and first-order tooth harmonic magnetic density of rotor.

(c) The third main components of the electromagnetic force: the low order force was caused by the interaction between 3 times of the fundamental flux density of rotor and first-order slot harmonic magnetic density of rotor and stator.

(d) The forth main components of the electromagnetic force: the electromagnetic vibration and noise sources of axial flux PMSM have been presented in this paper, which provides the theoretical support for the suppression of electromagnetic noise of axial flux PMSM.

\section{Conflict of Interests}

The authors declare that there is no conflict of interests regarding the publication of this paper.

\section{Acknowledgments}

The research leading to these results has received funding from the Research Foundation Program for Doctor of Liaoning Province (20131001) and the Polish-Norwegian Research Programme operated by the National Centre for Research and 24 Development under the Norwegian Financial Mechanism 2009-2014 in the frame of Project Contract no. PolNor/200957/47/2013.

\section{References}

[1] S. Yin, S. X. Ding, A. H. A. Sari, and H. Hao, "Data-driven monitoring for stochastic systems and its application on batch process," International Journal of Systems Science: Principles and Applications of Systems and Integration, vol. 44, no. 7, pp. 13661376, 2013.

[2] S. Yin, S. X. Ding, A. Haghani, H. Hao, and P. Zhang, "A comparison study of basic data-driven fault diagnosis and process monitoring methods on the benchmark Tennessee Eastman process," Journal of Process Control, vol. 22, no. 9, pp. 1567-1581, 2012.

[3] S. Yin, H. Luo, and S. Ding, "Real-time implementation of faulttolerant control systems with performance optimization," IEEE Transactions on Industrial Electronics, vol. 61, no. 5, pp. 240222411, 2013.

[4] S. Yin, X. Yang, and H. R. Karimi, "Data-driven adaptive observer for fault diagnosis," Mathematical Problems in Engineering, vol. 2012, Article ID 832836, 21 pages, 2012.

[5] X. Zhao, X. Liu, S. Yin, and H. Li, "Improved results on sta-bility of continuous-time switched positive linear systems," Automatica, 2013.

[6] X. Zhao, P. Shi, and L. Zhang, "Asynchronously switched control of a class of slowly switched linear systems," Systems \& Control Letters, vol. 61, no. 12, pp. 1151-1156, 2012.

[7] X. Zhao, L. Zhang, and P. Shi, "Stability of a class of switched positive linear time-delay systems," International Journal of Robust and Nonlinear Control, vol. 23, no. 5, pp. 578-589, 2013.

[8] X. Zhao, L. Zhang, P. Shi, and H. Karimi, "Robust control of continuous-time systems with state-dependent uncertainties and its application to electronic circuits," IEEE Transactions on Industrial Electronics, no. 99, 1 page, 2013.

[9] Z. Q. Zhu and D. Howe, "Instantaneous magnetic field distribution in permanent magnet brushless DC motors. Part IV: magnetic field on load," IEEE Transactions on Magnetics, vol. 29, no. 1, pp. 152-158, 1993.

[10] Y.-X. Chen, Z.-Q. Zhu, and S.-C. Ying, Analysis and Control of Moto, Zhejiang University Press, Hangzhou, China, 1987.

[11] Z. Q. Zhu, D. Howe, and C. C. Chan, "Improved analytical model for predicting the magnetic field distribution in brushless permanent-magnet machines," IEEE Transactions on Magnetics, vol. 38, no. 1, pp. 229-238, 2002. 
[12] Z. Q. Zhu, Z. P. Xia, L. J. Wu, and G. W. Jewell, "Analytical modelling and finite element computation of radial vibration force in fractional-slot permanent magnet brushless machines," in Proceedings of the IEEE International Electric Machines and Drives Conference (IEMDC '09), pp. 144-151, Miami, Fla, USA, May 2009.

[13] S. A. Long, Z. Q. Zhu, and D. Howe, "Vibration behaviour of stators of switched reluctance motors," IEE Proceedings: Electric Power Applications, vol. 148, no. 3, pp. 257-264, 2001.

[14] D. Žarko, D. Ban, and T. A. Lipo, "Analytical solution for cogging torque in surface permanent-magnet motors using conformal mapping," IEEE Transactions on Magnetics, vol. 44, no. 1, pp. 52-65, 2008.

[15] H. R. Izadfar, S. Shokri, and M. Ardebili, "Magnetic field analysis in permanent magnet synchronous machine by analytical method," in Proceedings of the International Conference on Electrical Machines and Systems (ICEMS '07), pp. 670-674, Seoul, South Korea, October 2007.

[16] X. Wang, Q. Li, S. Wang, and Q. Li, "Analytical calculation of air-gap magnetic field distribution and instantaneous characteristics of brushless DC motors," IEEE Transactions on Energy Conversion, vol. 18, no. 3, pp. 424-432, 2003.

[17] D. Žarko, D. Ban, and T. A. Lipo, "Analytical calculation of magnetic field distribution in the slotted air gap of a surface permanent-magnet motor using complex relative air-gap permeance," IEEE Transactions on Magnetics, vol. 42, no. 7, pp. 18281837, 2006.

[18] J. Azzouzi, G. Barakat, and B. Dakyo, "Quasi-3-D analytical modeling of the magnetic field of an axial flux permanentmagnet synchronous machine," IEEE Transactions on Energy Conversion, vol. 20, no. 4, pp. 746-752, 2005.

[19] F. Ishibashi, K. Kamimoto, S. Noda, and K. Itomi, "Small induction motor noise calculation," IEEE Transactions on Energy Conversion, vol. 18, no. 3, pp. 357-361, 2003.

[20] L. Yang, C. Lixiang, T. Renyuan, and C. Jian, “Test and analysis of vibration and noise for permanent magnet synchronous motor," Electrical Engineering, no. 4, pp. 18-20, 2009.

[21] S. Yu, J. Xu, Q. Zhao, and R. Tang, "Experimental research of permanent magnet synchronous motor vibration and noise characteristics," Journal of Northeastern University, vol. 23, no. 1, pp. S72-S76, 2002.

[22] S. Yu, Q. Zhao, and R. Tang, "Researches on noise and vibration characteristics of large-capacity permanent magnet synchronous machine," in Proceedings of the 5th International Conference on Electrical Machines and Systems (ICEMS '01), vol. 2, pp. 846-849, Shenyang, China, 2001.

[23] K.-T. Kim, K.-S. Kim, S.-M. Hwang, T.-J. Kim, and Y.-H. Jung, "Comparison of magnetic forces for IPM and SPM motor with rotor eccentricity," IEEE Transactions on Magnetics, vol. 37, no. 5 I, pp. 3448-3451, 2001.

[24] H.-S. Ko and K.-J. Kim, "Characterization of noise and vibration sources in interior permanent-magnet brushless DC motors," IEEE Transactions on Magnetics, vol. 40, no. 6, pp. 3482-3489, 2004.

[25] S. Yu and R. Tang, "Electromagnetic and mechanical characterizations of noise and vibration in permanent magnet synchronous machines," IEEE Transactions on Magnetics, vol. 42, no. 4, pp. 1335-1338, 2006. 


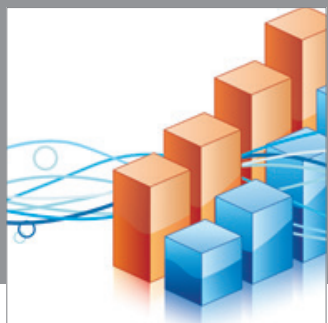

Advances in

Operations Research

mansans

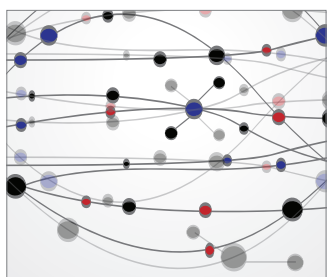

The Scientific World Journal
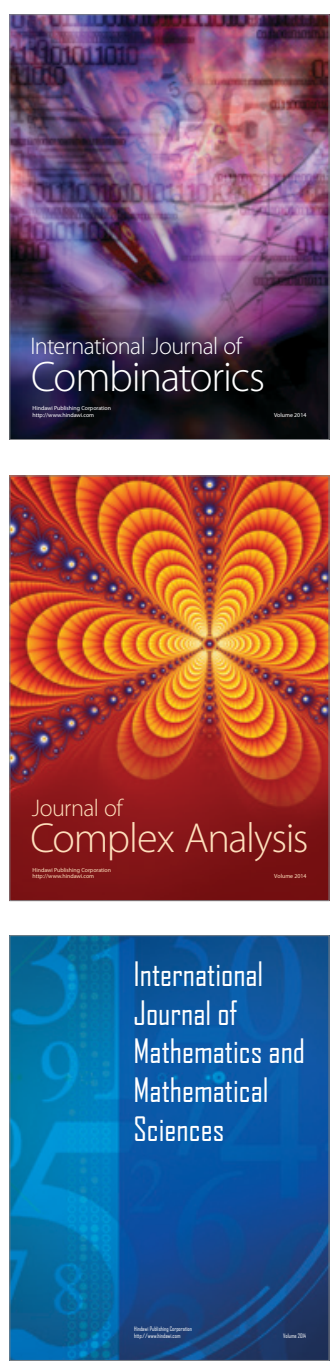
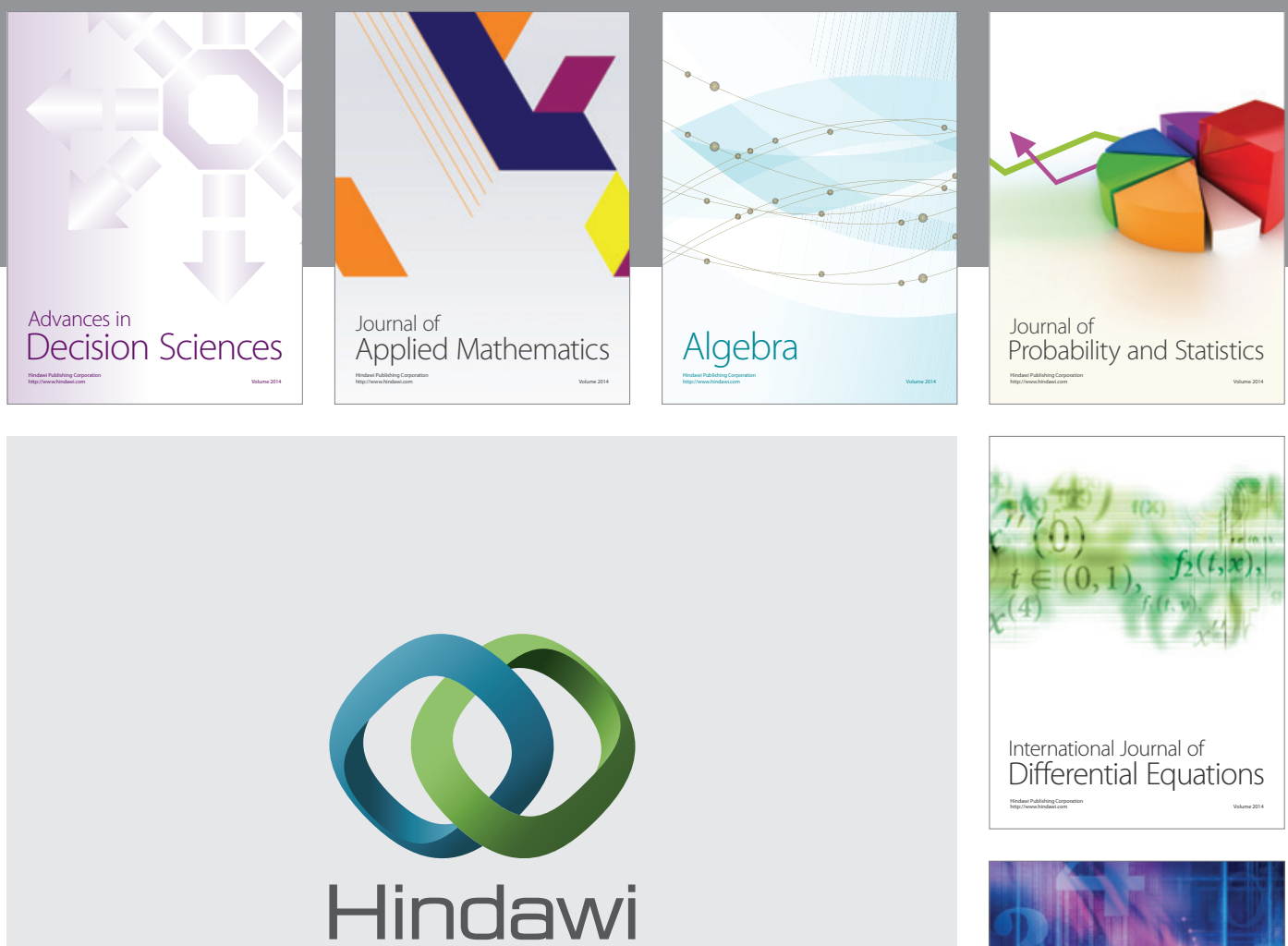

Submit your manuscripts at http://www.hindawi.com
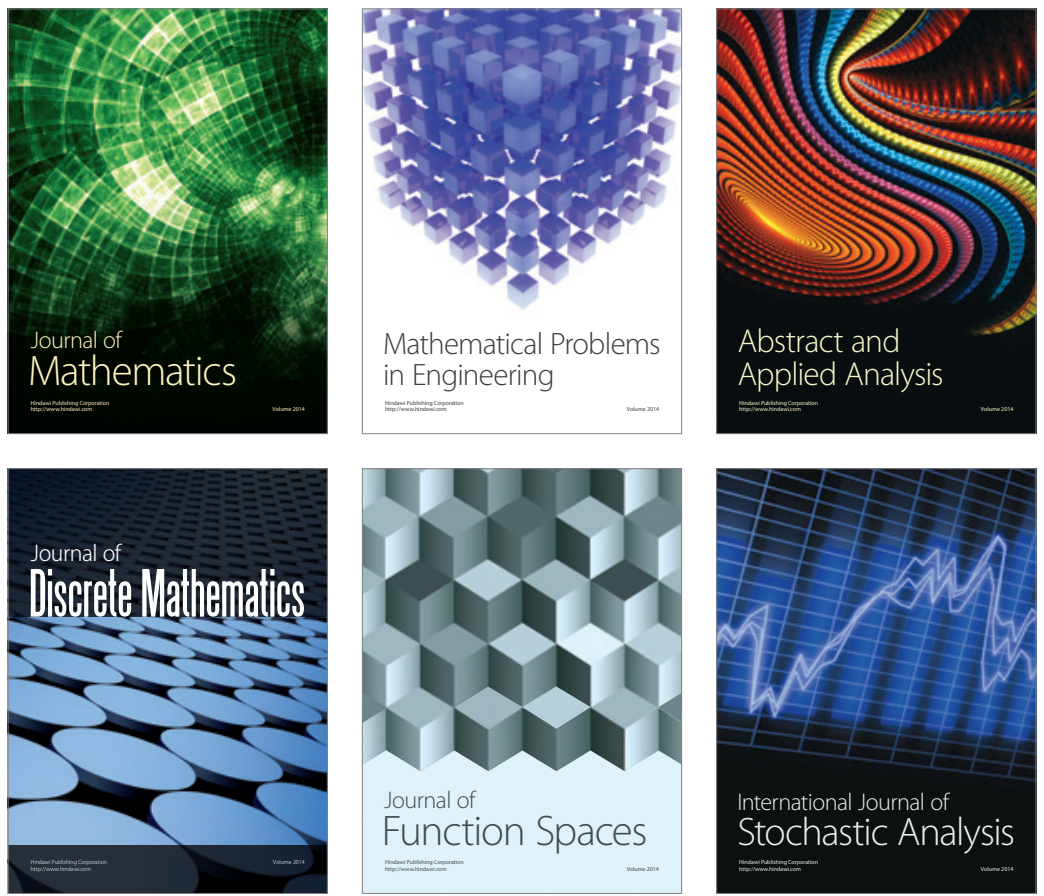

Journal of

Function Spaces

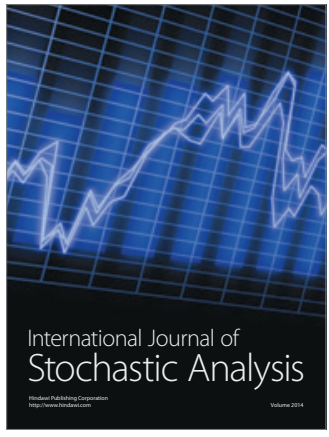

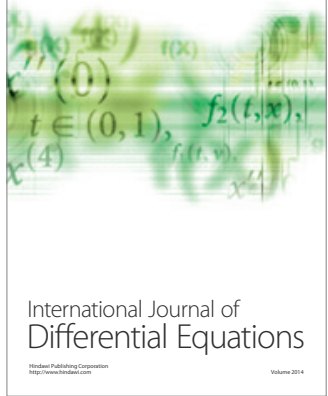
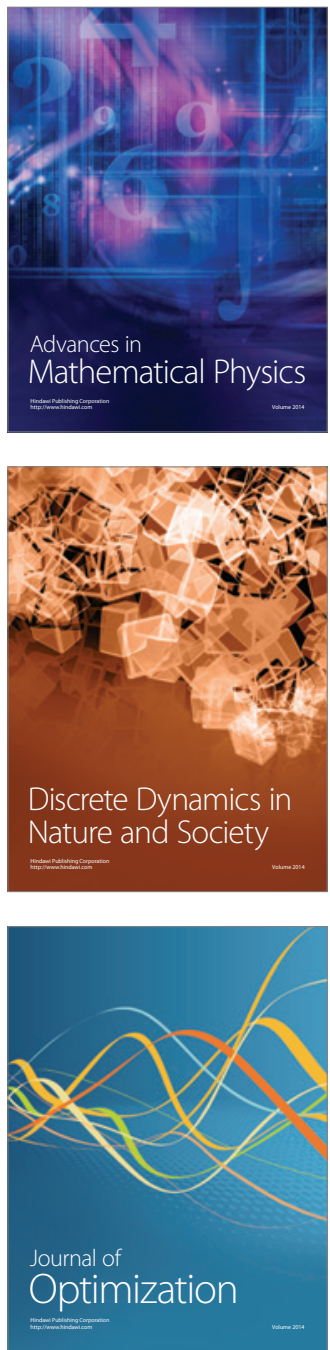